\title{
Population Dynamics of a Florida Citrus tristeza virus Isolate and Aphid-Transmitted Subisolates: Identification of Three Genotypic Groups and Recombinants After Aphid Transmission
}

\author{
Avijit Roy and R. H. Brlansky
}

University of Florida, IFAS, Plant Pathology Department, Citrus Research and Education Center, 700 Experiment Station Road, Lake Alfred 33850.

Accepted for publication 10 July 2009.

\begin{abstract}
Roy, A., and Brlansky, R. H. 2009. Population dynamics of a Florida Citrus tristeza virus isolate and aphid-transmitted subisolates: Identification of three genotypic groups and recombinants after aphid transmission. Phytopathology 99:1297-1306.

Tristeza is an important citrus disease affecting the viability and productivity of citrus worldwide. The causal agent, Citrus tristeza virus (CTV), usually occurs as a mixture of genotypes in nature, with one of the genotypes often dominating the population. CTV has a monopartite, positive-sense RNA genome of $\approx 19.3 \mathrm{~kb}$ and exhibits over $30 \%$ diversity in the $5^{\prime}$ half and less than $10 \%$ in the $3^{\prime}$ half among different genotypes. A Florida CTV isolate, FS627, was selected for this study. Isolate FS627 was analyzed by reverse-transcription polymerase chain reaction (RTPCR) using primers to three regions: 788-bp region in the 5' (697 to

confirmed utilizing the genotype specific overlapping region of RdRp primer pairs for RT-PCR amplification followed by cloning and sequence analysis. Analysis of single-strand conformational polymorphisms and sequences of RT-PCR-amplified products of the above regions were used to determine the presence of genotypes in both the parent and aphidtransmitted (AT) subisolates. Although the parent isolate had T36 as the major genotype, T30 was the major genotype in most of the AT subisolates. Some intermediate genotypes were detected that differed from the parental or AT subisolates. These intermediate genotypes were considered to be recombinants of the T30 and T36 genotypes and also were observed in the second level of AT subisolates generated from the of first-level AT subisolates of CTV-FS627. This work provides advance information on the population dynamics in CTV mixtures and the generation of virus recombinants after aphid transmission.
\end{abstract} 1,484 nucleotides), open reading frame (ORF)1a, 696 or $718 \mathrm{bp}$ from the overlapping region of the RdRp (ORF1b) and p33 (ORF2) gene, and a 672-bp major coat protein gene (ORF7) in the $3^{\prime}$ end of the CTV genome. The presence of T36, T30, and VT genotypes in isolate FS627 was
Additional keywords: aphid transmission, brown citrus aphid, Closterovirus, recombination, Toxoptera citricida.
Citrus tristeza virus (CTV), a Closterovirus in the family Closteroviridae, is a monopartite single-stranded RNA virus $\approx 19.3 \mathrm{~kb}$ in size that is phloem limited and transmitted in a semipersistent manner by different aphid species. The virions are filamentous, flexuous particles, 2,000 by $11 \mathrm{~nm}$ in size, with two coat proteins ( $\mathrm{CP}$ and $\mathrm{CPm}$ ) covering 95 and $5 \%$ of the particle length, respectively. The virus genome is organized into 12 open reading frames (ORFs) and encodes at least 19 protein products $(10,11,14,17)$ with untranslated regions (UTRs) of $\approx 107$ and 273 nucleotides (nt) at the $5^{\prime}$ and $3^{\prime}$ termini, respectively. The CTV genome exhibits $>30 \%$ diversity in the $5^{\prime}$ half and $<10 \%$ in the $3^{\prime}$ half of the different genotypes $(14,21)$. In most field trees, the virus exists as a complex or assortment of different virus strains or subisolates $(5,7)$. The strains present in one citrus-growing area in Florida may not be common in another area (7). Citrus and its relatives are the only natural hosts of CTV and the different biological symptoms caused by the virus, such as seedling yellows, tree decline, stem pitting, or mild variations of these symptoms found on different hosts. The exact mechanism of the interaction of the various strains or genotypes in the hosts to

Corresponding author: R. H. Brlansky; E-mail address: rhby@crec.ifas.ufl.edu

* The $e$-Xtra logo stands for "electronic extra" and indicates that Figures 5 and 6 appear in color online.

doi:10.1094/PHYTO-99-11-1297

(c) 2009 The American Phytopathological Society produce these different symptoms is unknown; however, the host type and certain environmental factors contribute to the symptom production (8).

The composition of different CTV complexes can be identified using various molecular methods, including the use of genotypespecific multiple molecular markers (MMM) using reverse-transcription polymerase chain reaction RT-PCR $(4,8,20)$ and strainspecific probe hybridization (15). Single aphid transmissions with the most efficient aphid vector, Toxoptera citricida Kirkaldy (brown citrus aphid [BCA]), have been shown to separate some of these isolate complexes $(4,5)$.

We reported previously (4) on the molecular analyses of various CTV isolate complexes and single-aphid-transmitted (SAT) subisolates using the mild and decline strain-discriminating monoclonal antibody MCA13 (18) and RT-PCR using CTV genotype-specific MMM developed by Hilf et al. (8). One of these CTV isolates was the Florida isolate FS627 that tested MCA13 positive serologically for the decline strain of CTV and was found by MMM to contain a mixture of T36, T30, and VT genotypes. After single-aphid transmissions, both MCA13 positive and negative subisolates with a mixture of genotypes were found (4).

The objective of this research was to determine which genotype was most frequently aphid transmitted (AT) from the parent isolate FS627. This was accomplished using single-strand conformation polymorphism (SSCP) and the population diversity was determined from three genomic regions of CTV by sequence analysis. 


\section{MATERIALS AND METHODS}

Virus isolates and subisolates. The Florida CTV isolate FS627 and its 14 BCA-transmitted subisolates were used in this study. Two levels of aphid transmissions were accomplished. In this study, first-level AT means subisolates transmitted from the parent CTV FS627 isolate whereas second-level AT subisolates were transmitted from the first-level AT subisolates. Four firstand second-level SAT and six second-level multiple aphid transmission (MAT) subisolates were included in this study. The Florida isolate FS627 has been described (4) and is serologically MCA13 positive, produces mild vein clearing symptoms in Mexican lime (Citrus aurantifoilia (L.) Swingle), and does not produce stem pitting or seedling yellows in sweet orange $(C$. sinensis (L.) Osb.) or grapefruit (C. paradisi Macf.). Genotype profile data has shown that FS627 was a mixture of T30, T36, and VT genotype isolates (4). The genotypic profile of the 14 AT subisolates has been generated using MMM and described (Table 1). Symptoms of the AT subisolates were similar to the parent isolate. The isolate and subisolates were maintained by bud grafting onto sweet orange and Mexican lime seedlings in the greenhouse.

Nucleic acid extraction, cDNA synthesis, and PCR amplification. Total RNA from infected leaf petioles and midribs and bark of the FS627 isolate and the AT subisolates was isolated using the RNeasy Plant Mini Kit (Qiagen, Valencia, CA). Total RNA isolated from healthy Mexican lime and sweet orange leaf petioles and bark was used as control for RT-PCR amplification. Oligonucleotide primers used to amplify the three different regions of the CTV isolate FS627 and subisolates were derived from CTV genomic sequences in the GenBank. The T36CP forward and reverse primers (8) were used to amplify the major coat protein gene (CPG). Genotype-specific polymerase (POL) primer pairs (8) were used to amplify the overlapping region of the RdRp and $p 33$ genes. Degenerate primer pairs CN487/489 and CN488/491 were used to amplify the 409 nucleotides (nt) (697 to $1,105 \mathrm{nt})$ and $403 \mathrm{nt}(1,082$ to $1,484 \mathrm{nt})$, respectively, from the 5' end of ORF1a of the CTV genome (21). Nucleotide numbering is based on the genome of the CTV T30 isolate (AF260651). The protocol for cDNA synthesis and PCR amplification has been described (4). Agarose gels $(0.8 \%)$ containing ethidium bromide at $500 \mathrm{ng} / \mathrm{ml}$ were used to analyze the PCR products. Throughout

TABLE 1. Population diversity in the coat protein gene (CPG) region of FS627 and its 14 aphid-transmitted (AT) subisolates

\begin{tabular}{|c|c|c|c|c|}
\hline \multirow[b]{2}{*}{$\mathrm{CTV}^{\mathrm{a}}$} & \multirow[b]{2}{*}{ Genotypes $^{\text {b }}$} & \multirow{2}{*}{$\frac{\text { ELISA }^{c}}{\text { MCA13 }^{c}}$} & \multicolumn{2}{|c|}{$\begin{array}{l}\text { Types of CPG } \\
\text { sequences found }\end{array}$} \\
\hline & & & T36-Like & T30-Like \\
\hline FS627 & T36, T30, VT & + & + & + \\
\hline AT1 & $\mathrm{T} 30$ & - & - & + \\
\hline AT9 (5/21/98) & T36 & - & - & + \\
\hline AT9 (5/12/99) & T36, T30 & + & + & + \\
\hline AT10 & T36, T30 & + & - & + \\
\hline AT1.11 & Т36, Т30 & - & - & + \\
\hline AT1.12 & T30, VT & - & - & + \\
\hline AT9.4 & T30 & + & + & + \\
\hline AT9.6 & T30, VT & - & - & + \\
\hline AT9.10 & T36, T30 & - & - & + \\
\hline AT9.11 & T30, VT & - & - & + \\
\hline AT9.12 (5/12/99) & T30, VT & - & - & + \\
\hline AT9.12 (12/01/99) & T36, VT & + & + & - \\
\hline AT10.10 & T30, VT & - & - & + \\
\hline AT10.11 & T30 & - & - & + \\
\hline
\end{tabular}

a Citrus tristeza virus (CTV) isolates and subisolates.

b Genotypes present based on multiple molecular markers.

c Symbols: $+=$ positive monoclonal antibody reaction (MAb) in enzymelinked immunosorbent assay (ELISA), whereas $-=$ no MAb reaction.

d Symbols: $+=$ presence of particular genotype sequence, whereas $-=a b-$ sence of particular genotype sequence. this article, the amplified PCR products from overlapping regions of the RdRP and p33 gene is designated as 'POL'.

SSCP analyzed nucleotide sequence variations and rapid differentiation of DNA fragments. For SSCP analysis, $1 \mu \mathrm{l}$ of the PCR-amplified product was mixed with $9 \mu$ of the denaturing solution (95\% formamide; $20 \mathrm{mM}$ EDTA, $\mathrm{pH} \mathrm{8;} \mathrm{0.05 \%} \mathrm{bromo-}$ phenol blue; and $0.05 \%$ xylene-cyanol), heated for $10 \mathrm{~min}$ at $99^{\circ} \mathrm{C}$, and immediately chilled on ice. Denatured DNA was electrophoresed in a nondenaturing $10 \%$ polyacrylamide Bio-Rad Ready-Gel (catalog 161-1110; Bio-Rad, Hercules, CA) using Tris-borate EDTA (89 mM Tris-borate and $2 \mathrm{mM}$ EDTA, pH 8.0) as an electrophoresis buffer and a constant voltage of $250 \mathrm{~V}$ for $4 \mathrm{~h}$ or $350 \mathrm{~V}$ for $3 \mathrm{~h}$ at $4^{\circ} \mathrm{C}(22)$. The gels were stained with ethidium bromide $(500 \mathrm{ng} / \mathrm{ml})$, and the resulting bands were viewed using a UV-transilluminator lamp (Ultra Violet Product, Upland, CA) and photographed.

cDNA cloning, sequencing, and sequence analyses. Nucleotide sequences from three different regions of CTV genome were determined for the isolate FS627 and its 14 AT subisolates. The primer-pair-amplified RT-PCR products were cloned into a pGEM-T Easy vector (Promega Corp., Madison, WI) using T4 DNA ligase according to the manufacturer's protocol, followed by transformation into Escherichia coli JM109. In all, 100 clones of the cDNA product obtained from the FS627 isolate and 50 clones from each of the first-level and second-level transmissions were selected and amplified by PCR under the same PCR conditions as described above. SSCP analysis was performed on the resulting PCR products mentioned above (22) to identify the different haplotypes and to reduce the number of clones to be sequenced. The nucleotide sequences of the clones were determined using the dye terminator method in an Applied Biosystems Model 3100 genetic analyzer (Perkin-Elmer Corp.) at the University of Florida (DNA Sequencing Core Laboratory, Gainesville). In all cases, at least five clones were sequenced. All sequence alignments were constructed by using Clustal X (version 1.8) (26). In order to achieve optimal results, different values for the gap opening and gap extension penalty and manual rearrangements of the alignment were applied. Percent identity matrices and nucleotide sequence alignments for each isolate were generated using GeneDoc (16). The MEGA3.1 package was used to perform the phylogenetic and distance analyses based on the sequences excluding gap-containing regions (12). Trees were constructed after bootstrapping to 1,000 replicates by the neighbor-joining method using the Jukes-Cantor parameter. Two other parameters, Tajima-Nei and Kimura-2, also were used for comparison. Minimum evolution (ME) and maximum parsimony (MP) methods also were applied in parallel for comparison. Trees based on sequences of the isolate FS627 and its AT subisolates from the CPG 5' terminal region and POL were rooted by using sequences of the corresponding gene sequence from nine fully sequenced CTV isolates (T30 [accession no. AF260651], T36 [accession no. U16304], T318A [accession no. DQ151548], T385 [accession no. Y18420], VT [accession no. U56902], SY568 [accession no. AF001623], Mexican CTV isolate [accession no. DQ272579], NUagA [accession no. AB046398], and Qaha from Egypt [accession no. AY340974]) retrieved from the National Center for Biotechnology Information database. In an attempt to detect putative intragenic recombinant isolates, the phylogeny of gene segments was determined with the program PHYLPRO (28). The program was used to detect recombinant sequences, identify recombinant junctions utilizing the pairwise distances of all sequences, and evaluate which patterns of distances in these regions agree. Using a 40-nt sliding window, the genes were scanned and compared. Each genetic group consensus sequence was used as the reference sequence for the recombinant isolate and subisolates. In total, 97 nucleotide sequences from CPG and POL and 697 to $1,484 \mathrm{nt}$ from the $5^{\prime}$ terminal region of CTV-FS627 and its AT subisolates were deposited in the 
GenBank database under accession numbers DQ355032 to DQ355128.

\section{RESULTS}

Diversity of CTV genomic RNA (gRNA) populations of AT subisolates of isolate FS627 analyzed by PCR at three different regions by their SSCP profiles. To detect the most frequent CTV genotype after aphid transmission by $T$. citricida, the SSCP profiles of CPG (p25), partial 5' terminal region (nucleotides 697 to 1,105 and 1,082 to 1,484 ), and POL, RT-PCRamplified products from the field isolate FS627 and its 14 AT subisolates were compared. The expected size of RT-PCRamplified products for the selected gene regions were 403 and 409 (5' end), 672 (CPG), and 696 or 718 nucleotides (POL). SSCP analysis of the three amplified products (except POL) of isolate FS627 had an electrophoretic profile with more than two bands (Fig. 1A, B, and C), which suggested that the isolate contained more than one sequence variant of gRNA at detectable concentrations. Analysis of the parent isolate FS627 with the POL primer pairs showed the presence of all three genotypes (T30, T36, and VT) and showed three different patterns of electrophoretic mobility between two bands (data not shown). Comparison of the SSCP profiles with the AT subisolates showed that most of the subisolates had two bands in either the first or second level of transmission (except Fig. 1A, lanes 12 and 13; B, lane 12; and $\mathrm{C}$, lanes 12 to 16 ).

SSCP analysis of CPG products revealed that the field isolate FS627 had an electrophoretic profile of more than two bands (Fig. 1A). Three of four first-level AT subisolates contained two bands whereas one subisolate (AT9 [5/12/98]) showed bands similar to the FS627 isolate. In the second level of transmissions, the subisolates contained two or more bands (Fig. 1A). Three distinct electrophoretic mobility patterns were obtained in SSCP analysis when compared with the FS627 isolate and subisolates with standard CTV genotypes. Of the 14 first- and second-level subisolates, T30- and T36-like banding patterns were obtained in 10 and 2 subisolates, respectively (Fig. 1A). No VT genotype-like banding pattern was obtained.
SSCP analysis of the amplified product of the overlapping region of 697 to 1,105 and 1,082 to $1,484 \mathrm{nt}$ from $5^{\prime}$ terminal region (Fig. 1B and C) and POL primer-amplified product (not shown) showed banding patterns similar to those observed with the CPG. Profiles with two DNA bands were observed among most of the first- and second-level AT subisolates, whereas three or more bands of similar intensity also were obtained in FS627, AT9(5/12/99), and two different AT9.12 subisolates (Fig. 1A and B). Comparison of SSCP profiles from first- and second-level AT subisolates from four different amplified products showed that most but not all subisolates had similar banding patterns (Fig. 1A to $\mathrm{C})$. The T30 genotype was observed more frequently than the T36 genotype based on SSCP pattern of CPG, 5' terminal region, and POL primer-amplified products.

Screening for the divergent genotypic population from the CPG. Sequencing of individual cDNA clones of the CPG from FS627 and the AT subisolates showed the presence of both T30 and T36 sequences in MCA13-positive subisolates (Table 1). In addition, the subisolate AT10, which was MCA13 positive, contained only the T30-like sequence (99\% sequence identity). No T36-like sequences were detected from MCA13-negative isolates (Table 1).

Phylogenetic analysis of the predominant sequence variants of CPG. The predominant sequence variant of each subisolate was chosen based on similar SSCP patterns of the cDNA clone. The SSCP pattern of most of the subisolates had only two DNA bands, whereas a more complex pattern was obtained for some subisolates. Three clones from each subisolate were selected for sequence analysis that showed identical SSCP patterns. The most variability was observed among clones of FS627, AT9 (5/12/98), and AT9.4. To assess the reliability of SSCP analysis to differentiate among CPG sequence variants, four clones from isolate FS627, AT9 (5/12/98), and AT9.4 were sequenced. The intragroup genetic diversity for group I (T36-like) and group II (T30-like) was $0.0069 \pm 0.0019$ and $0.0035 \pm 0.0008$, respectively (Table 2A). Most of the clones with the same SSCP pattern differed by 0 to $4 \mathrm{nt}$. On the other hand, the maximum nucleotide distance found between two clones with different SSCP patterns was 0.0074 and 0.0119 for groups I and II, respectively. These data

A
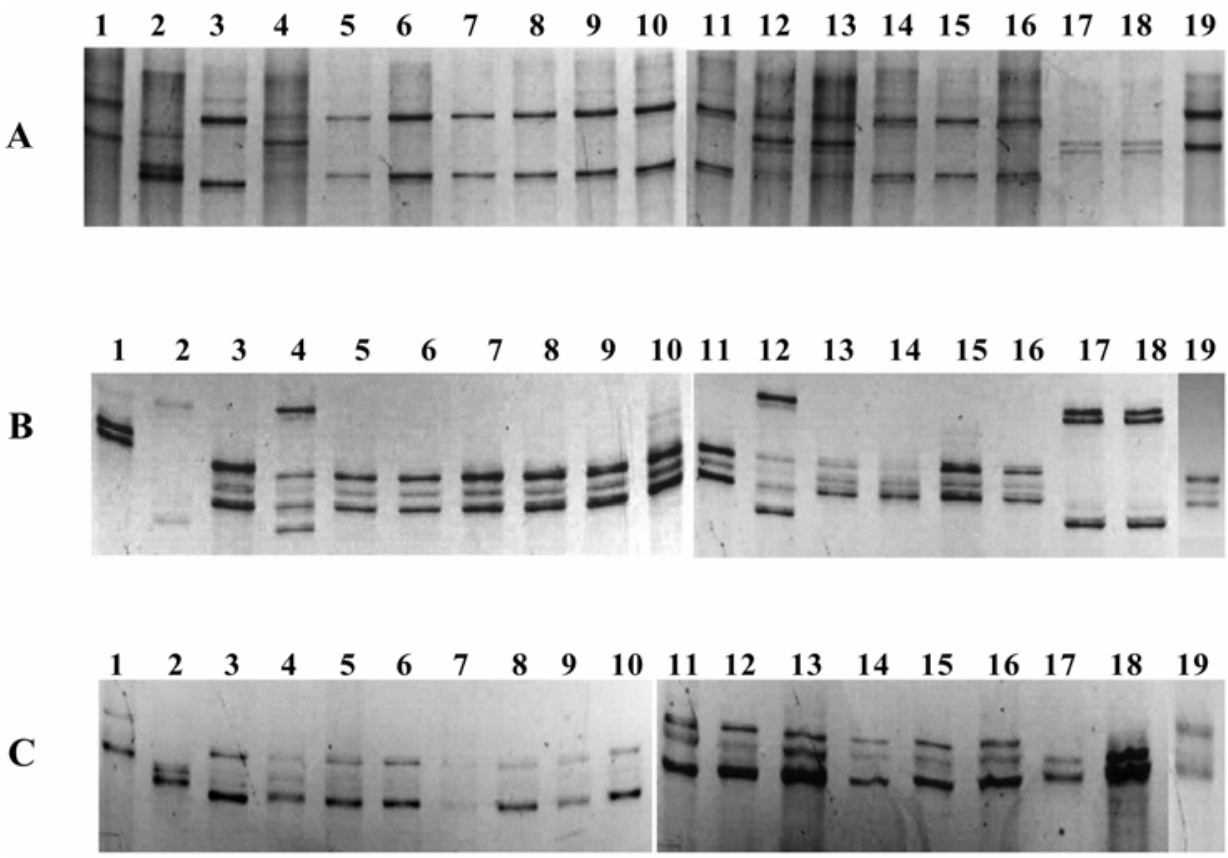

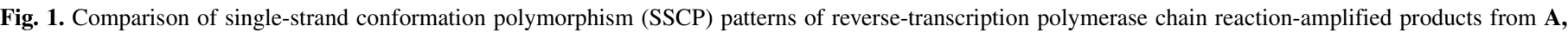

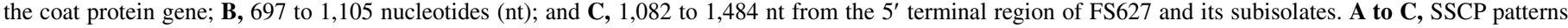

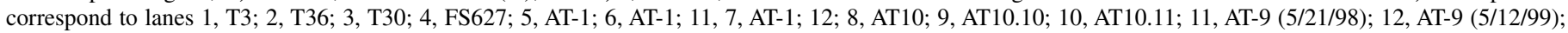
13, AT-9.4; 14, AT-9.6; 15, AT-9.10; 16, AT-9.11; 17, AT-9.12 (5/12/99); 18, AT9.12 (12/1/99); and 19, B395 (VT). 
indicate that SSCP analysis was a reliable procedure to differentiate sequence variants of the CPG gene.

The phylogenetic analysis of the predominant CPG sequence variants of FS627 and its 14 subisolates, using the neighborjoining relationships based on pairwise comparison of JukesCantor parameter method, showed a dendrogram in which two groups of subisolates shared the clade with the T30 and T36 genotypic isolates (Fig. 2). Group I (T36) and group II (T30) isolates were called the decline and mild group, respectively. Group III includes the sequences of stem pitting and seedling yellows isolates from GenBank. Although T3 sequences were included in group III, the maximum pairwise distance between

TABLE 2. Intragroup (A) and intergroup (B) genetic diversity values from coat protein gene (CPG), nucleotides 697-1,105 (697 nt) and 1,082-1,484 (1,082 nt) of open reading frame (ORF)1a were estimated for the T36 severe decline, T30 mild, and stem pitting and seedling yellows producing Citrus tristeza virus (CTV) VT-like isolates ${ }^{\mathrm{a}}$

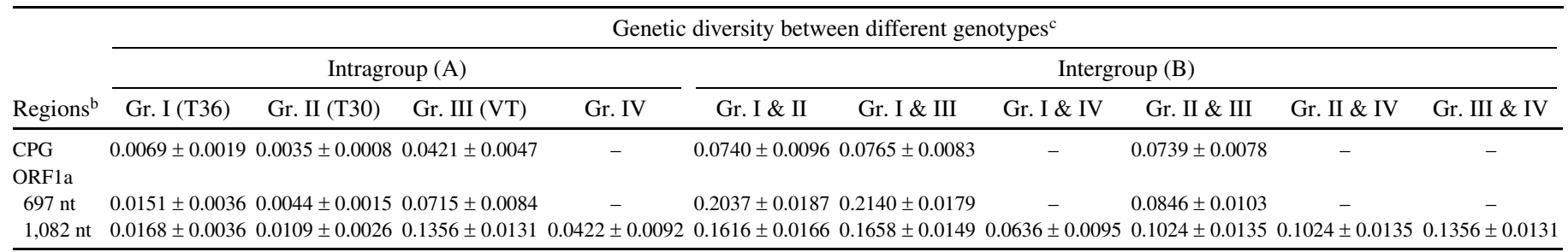

a Nucleotide distances were calculated with the MEGA3.1 program.

${ }^{\mathrm{b}}$ CTV genomic regions.

${ }^{c}$ Groups (Gr.) and combinations of groups; group IV = recombinant. - indicates that the value is undermined.

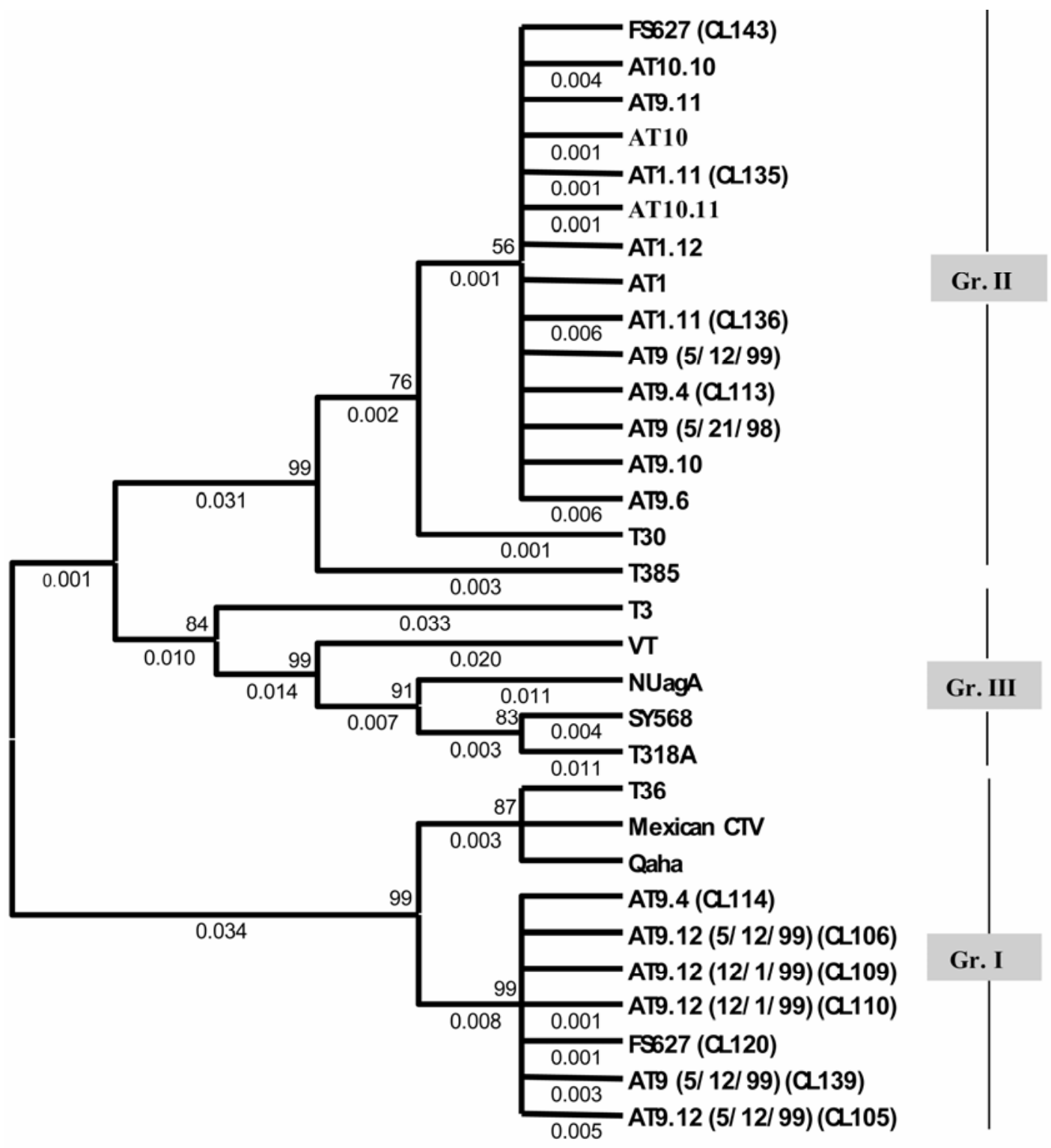

Fig. 2. Neighbor-joining dendrogram depicting phylogenetic relationships based on pairwise comparison using the Jukes-Cantor parameter on nucleotide sequences from the coat protein gene (CPG) of the Citrus tristeza virus genome. Upper and lower branch points are indicated bootstrap values (1,000 replicates) supporting a particular phylogenetic group and the scale bar represents nucleotides substitution per site, respectively. All the CPG nucleotide sequences were deposited in the GenBank database under accession numbers DQ355032 to DQ355053. 
the sequence of T3 and other members of group III was greater (0.0655).

The intragroup and the intergroup genetic diversity (average nucleotide distance between any two randomly selected isolates of the same group or one of each group) were summarized in Table 2A and B. The intragroup diversity of the severe (T36) and the mild (T30) isolate was 10 - to 20 -fold smaller than their intergroup diversity. The intragroup diversity of group III isolates was twofold less than the intergroup values. All the statistical analyses were established with the topology of the phylogenetic tree. No evidence of recombination was obtained for the CPG sequences from isolates of the mild group (T30) or from those of the severe group (T36).

Screening the divergent genotypic population from nucleotides 697 to 1,484 in the $5^{\prime}$ region. SSCP and sequencing analysis were used to find the variation among the amplified products of CN487/CN489 (697 to $1,105 \mathrm{nt}$ ) and CN488/CN491 $(1,082$ to $1,484 \mathrm{nt})$ and their clones. The presence of two or more distinct banding patterns and their sequence analysis confirmed the presence of T30 (98 to 100\% sequence identity) and T36 (96 to $98 \%$ sequence identity) similar to CTV populations in FS627. To determine whether the population contained more haplotypes, we screened the transformed colonies from each amplified product of FS627 and its subisolates. A minimum of
50 colonies was screened from each amplified product. We did not find any sequence variants except for the amplified product of $\mathrm{CN} 488 / 491$ (1,082 to $1,484 \mathrm{nt}$ ). The number of colonies screened and the variants are summarized in Table 3. Variants were found in the parent isolate FS627 and the secondlevel subisolate AT9.4 but no variants were seen in first-level subisolates. The percentage of variants of the genotypic population was 0.8 to 2.0 .

Phylogenetic analysis of the predominant sequence variants from the $5^{\prime}$ region $(697$ to $1,484 \mathrm{nt})$. Two sets of primers (CN487/CN489 and CN487/491) were used to amplify the overlapping regions of nucleotides 697 to 1,484 from the $5^{\prime}$ terminal region of CTV genomes and were analyzed. Sequence analysis of $409 \mathrm{nt}$ (697 to $1,105 \mathrm{nt}$ ) amplified by primer pair CN487/CN489 indicated three genogroups (Fig. 3A); however, a phylogram displaying the sequence analyses of the $403 \mathrm{nt}(1,082$ to $1,484 \mathrm{nt})$ amplified by primer pair CN488/491 indicated four genogroups (Fig. 3B). The FS627 isolate (CL201) and AT9.4 (CL208) represented the new clades in the phylogenetic tree (Fig. 3B). This indicates that sequence diversity is greater in the second half of the $788 \mathrm{nt}$ in the $5^{\prime}$ terminal region. The differences in genogrouping in the dendrograms based on nucleotide sequences of these two overlapping regions also indicate possible recombinations in some of the cloned sequences.

TABLE 3. Screening of divergent genotypic populations of 1,082-1,484-nucleotide genomic RNA of FS627 and its first- and second-level aphid-transmitted (AT) subisolates

\begin{tabular}{lcccccc}
\hline & & \multicolumn{3}{c}{ Percentage of genotype population } \\
\cline { 3 - 6 } Isolates $^{\mathrm{a}}$ & No. of clones tested & T3 & T30 & T36 & VT & New variants \\
\hline FS627 & 100 & 0 & 26.00 & 72.00 & 0 & 2.0 \\
First-level transmission & 200 & 0 & 83.33 & 16.77 & 0 & 0 \\
Second-level transmission & 500 & 0 & 80.00 & 19.20 & 0 & 0.8 \\
\hline
\end{tabular}

${ }^{a}$ First-level AT isolates included AT1, AT9 (5/21/98), AT9 (5/12/99), and AT10 and second-level AT isolates included AT1.11, AT1.12, AT10.10, AT10.11, AT9.4, AT9.6, AT9.10, AT9.11, AT9.12 (5/12/99), and AT9.12 (12/1/99).

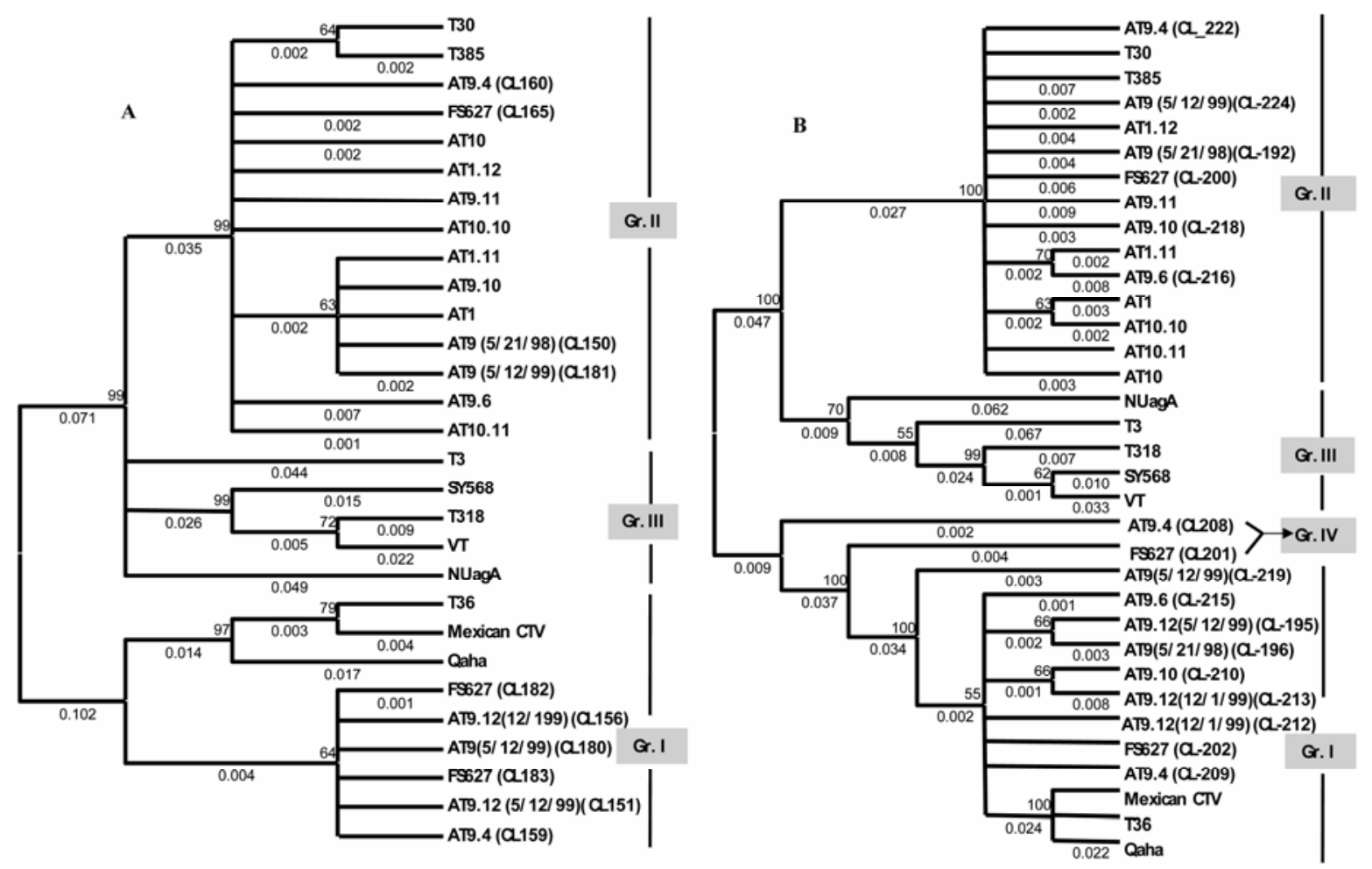

Fig. 3. Neighbor-joining dendrogram depicting phylogenetic relationships based on pairwise comparison using the Jukes-Cantor parameter on nucleotide sequences from A, 697 to 1,105 nucleotides (nt) and B, 1,082 to 1,484 nt of the Citrus tristeza virus genome. Upper and lower branch points are indicated bootstrap values (1,000 replicates) supporting a particular phylogenetic group and the scale bar represents nucleotides substitution per site respectively. All the nucleotide sequences included were deposited in the GenBank database under accession numbers A, DQ355086 to DQ355104 and B, DQ355105 to DQ355128. 
Intragroup and intergroup genetic diversities were summarized in Table 2A and B. The intragroup diversity of T36 and T30 isolates were 13- to 46-fold less than the intergroup diversity. In the CN487/489 amplified sequences, the intergroup diversity of the group III isolates was similar to group II isolates and twofold less than the intragroup values of group I. Evidence for recombination was obtained for the CN488/491-amplified sequences from isolate FS627 and subisolate AT9.4. The intragroup diversity of the group IV recombinant sequences was close to T36 genotype but two- to threefold less than T30 and other genotypes. The topology of the phylogenetic tree confirmed the result of statistical analysis.

Molecular profiles based on POL MMM. The molecular profiles of FS627 and its AT subisolates were previously determined by Brlansky et al. (4). After 3 years, the isolate and subisolates were retested using MMM primer pairs (8). Differences were found in the profiles among three AT subisolates but the original FS627 isolate remained constant in the original source plant. The subisolates AT1 and AT9 (5/21/98) were amplified by VTPOL primers but AT9.10 no longer was amplified with the T36POL primers (Table 4).

Phylogenetic analysis of the predominant sequence variants of the POL region. The genotype-specific POL primer pair is one of the most critical MMM for genotyping of CTV isolates. In sequence analysis of the CPG and 5' terminal region sequence, we did not find any sequence similar to the VT genotype. However, the MMM profile of isolate FS627 showed that the isolate contains a mixture of T30, T36, and VT genotypes. Because of these results, the POL primer-amplified products from FS627 and its AT subisolates were cloned and sequenced. All probable divergent CTV populations from transformed colonies were screened. The T36POL-amplified products shared 97 to $98 \%$ sequence identity with the T36 decline CTV isolate, whereas T30POL-amplified products contained 98 to $99 \%$ sequence similarity with the T30 mild isolate. The original isolate FS627 and eight AT subisolates produced VTPOL-amplified products. Only isolate FS627 and two subisolates (AT9 [5/21/98] and AT9.12 [12/1/99]) showed sequence identity (94 to $96 \%$ ) with the VT isolate. Six amplified product sequences (CL-228, -232, -234, $-239,-241$, and -241 ) had only an $84 \%$ sequence identity with the VT isolate. A sequence identity of 98 to $99 \%$ with the T30 genotype placed them in clade II of the phylogenetic tree (Fig. 4, subgroup II-b). The intergroup diversity of subgroup II-a and subgroup II-b isolates was $0.0309 \pm 0.0036$ (Table 5). The nucleotide changes affect the clade position of the variants in the phylogenetic tree.
Identification of CTV recombinants. Sequence alignment of the 403-nt $(1,082$ to 1,484) amplicon clones CL201 and CL205 of FS627 and CL208, CL209, CL216, and CL218 of AT9.4 with T30 and T36 isolate sequences indicates the presence of mixed sequences in FS627 and its second-level subisolate. Five of the clones sequenced from each CN488/491-amplified product were outliers within their own sequence alignment followed by phylogenetic analysis, which suggests the occurrence of recombination (Figs. 3 and 5). Two recombinant clones of FS627 and four clones of AT9.4 subisolate shared an intraclone sequence identity of $100 \%$ between them. The representative clones CL201 and CL208 had T36-like sequences in the beginning of the CN488/491-amplified product and were mutated at the 190th nt position (Fig. 5). As a result of mutation, clones CL201 and CL208 exchanged 108 and 198 nt, respectively, with the sequence of T30 isolate and continued with the T36 sequence. Clones CL201 and CL208 had maximum nucleotide sequence identity with T36 (93\%) and T30 (91\%) isolates, respectively. The mean distance within CL201 and CL208 was $0.0422 \pm 0.0092$, whereas intergroup similarity of recombinants with groups I and II was $0.0636 \pm 0.0095$ and $0.1024 \pm 0.0135$ (Table 2B).

The correlation of the phylogenetic profiles of the $5^{\prime}$ end sequences $(1,082$ to $1,484 \mathrm{nt})$ from a set of CTV isolates and subisolates were graphically displayed using the PHYLPRO computer program (28) (Fig. 6). Results present evidence of recombination in isolate FS627 and its second-level AT subisolate, AT9.4. The presence of two sharp downward peaks at the 175th and 295th nt corresponds to -0.025 and -0.1 correlation coefficients, indicating recombination for the isolate FS627 (CL201). The subisolate AT9.4 (CL208) also showed recombination at the 210th nt position, corresponding to -0.5 correlation coefficient. These data suggest the occurrence of recombination events in this region of the genome among the FS627 and its subisolates. When other CTV sequences from the GenBank (described in text) were added and compared, isolates T30 and T318A were identified as recombinants in the same region of the genome, similar to CL201 and CL208 (Fig. 6). Isolate T318A showed recombination at the 1163rd and 1285th nt positions (83rd and 205th based on amplicon), whereas, in the isolate $\mathrm{T} 30$, recombination had occurred at the 1211st nt (130th based on amplicon) position.

\section{DISCUSSION}

In most field trees, CTV occurs as a complex or assortment of different virus strains or subisolates that are known to differ in

TABLE 4. Profile of FS627 and aphid-transmitted (AT) subisolates using multiple molecular markers (MMM) genotype-specific POL primer pairs

\begin{tabular}{|c|c|c|c|c|c|}
\hline \multirow[b]{2}{*}{ Isolates } & \multirow[b]{2}{*}{ Category ${ }^{a}$} & \multirow[b]{2}{*}{ Dates for aphid transmission study } & \multicolumn{3}{|c|}{$\mathrm{MMM}^{\mathrm{b}}$} \\
\hline & & & T36POL & T30POL & VTPOL \\
\hline FS627 & Field & $\ldots$ & + & + & + \\
\hline AT1 & SAT & $12 / 23 / 97$ & - & + & $-1+$ \\
\hline AT9 & SAT & $05 / 12 / 99$ & + & + & - \\
\hline AT10 & SAT & $12 / 23 / 97$ & + & + & _- \\
\hline AT1.11 & SMAT & $12 / 01 / 99$ & + & + & - \\
\hline AT9.10 & SSAT & $05 / 12 / 99$ & $+/-$ & + & - \\
\hline AT9.11 & SMAT & $05 / 12 / 99$ & - & + & + \\
\hline AT9.12 & SMAT & 05/12/99 & - & + & + \\
\hline AT9.12 & SMAT & $12 / 01 / 99$ & + & - & + \\
\hline AT10.10 & SSAT & $12 / 09 / 98$ & - & + & + \\
\hline AT10.11 & SMAT & $12 / 09 / 98$ & - & + & - \\
\hline
\end{tabular}

a SAT: single-aphid transmission, SMAT: single- followed by multiple-aphid transmission, and SSAT: single- followed by single-aphid transmission.

${ }^{\mathrm{b}}$ MMM was used to determine the genotype profile of all the AT subisolates at 6-month intervals from 2004 to 2008 . Positive $(+)$ areas indicate polymerase chain reaction amplification, negative $(-)$ areas indicate no amplification with the genotype-specific MMM primer pairs, areas with $-/+$ indicate amplification by VTPOL primers, and areas with $+/-$ indicate no longer amplified with the T36POL primers. 
their aphid transmissibility $(4,5,19)$. Transmission with Aphis gossypii frequently altered the populations of gRNAs and D-RNAs with Spanish and Japanese CTV isolates (1). The presence of hidden severe isolates with mild isolates was found with Australian, Floridian, and Corsican isolates and, single-BCA transmission was used as a tool for separation $(4,5,9)$. The genotype profiles of three different Florida isolates were studied in three citrus hosts and the profiles did not change upon bud graft transmission (A. Kahlon and R. H. Brlansky, unpublished data).
The objective of our present work was to characterize the most frequently transmitted genotypes from a naturally mixed infected CTV isolate FS627 and its AT subisolates. For this purpose, 4 first-level and 10 second-level FS627 subisolates were generated. Genotype profiles of the 14 subisolates have been previously determined (4) and also retested after 3 years. Recent work on utilization of MMM primer pairs in the regions of POL and ' $\mathrm{k} 17$ ' of the CTV genome of Indian CTV isolates showed that amplifications were not always genotype specific (21). Using SSCP analysis of different genomic regions, Ayllon et al. (3)

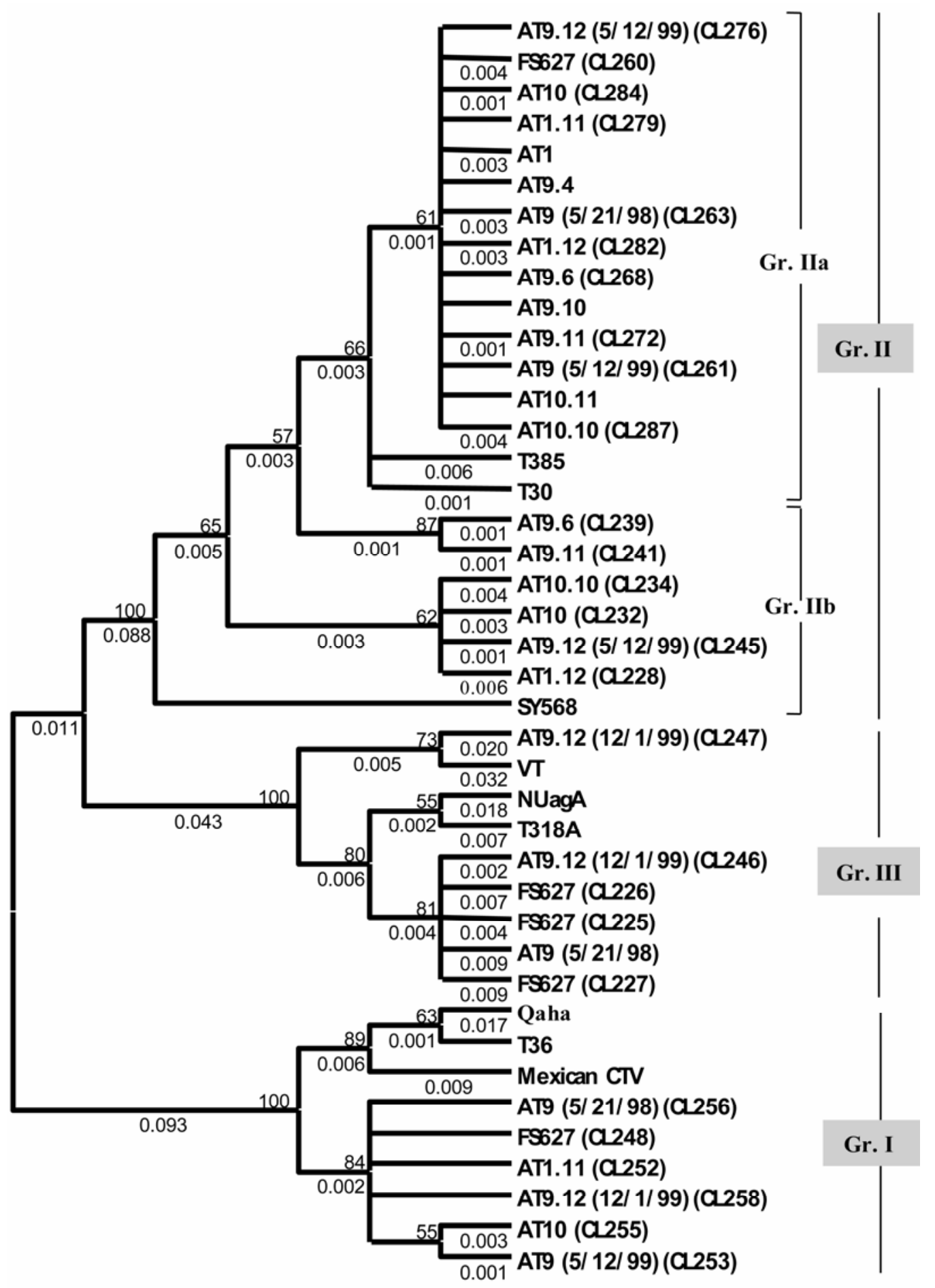

Fig. 4. Neighbor-joining dendrogram depicting phylogenetic relationships based on pairwise comparison using the Jukes-Cantor parameter on 696/718 nucleotides sequence from the genotype-specific polymerase (POL) region of the Citrus tristeza virus genome. Upper and lower branch points are indicated bootstrap values (1,000 replicates) supporting a particular phylogenetic group and the scale bar represents nucleotides substitution per site, respectively. All the nucleotide sequences were deposited in the GenBank database under accession numbers DQ355054 to DQ355085. 
TABLE 5. Intra and intergroup genetic diversity values from genotype-specific POL region were estimated for T36 severe decline, T30 mild, and stem pitting and seedling yellows producing Citrus tristeza virus VT-like isolates ${ }^{\mathrm{a}}$

\begin{tabular}{llcccc}
\hline & Genotype & Group I & Group II-a & Group II-b & Group III \\
\hline Group I & T36 & $0.0106 \pm 0.0020$ & $0.0861 \pm 0.0143$ & $0.1588 \pm 0.0130$ & $0.1783 \pm 0.0138$ \\
Group II-a & T30 & $\ldots$ & $0.0037 \pm 0.0008$ & $0.1504 \pm 0.0125$ & $0.0121 \pm 0.0027$ \\
Group II-b & T30/VT & $\ldots$ & $\ldots$ & $0.0309 \pm 0.0036$ & $0.1420 \pm 0.0119$ \\
Group III & VT & $\ldots$ & $\ldots$ & $\ldots$ & $0.0098 \pm 0.0021$ \\
\hline
\end{tabular}

${ }^{a}$ Nucleotide distances were calculated with the MEGA3.1 program.

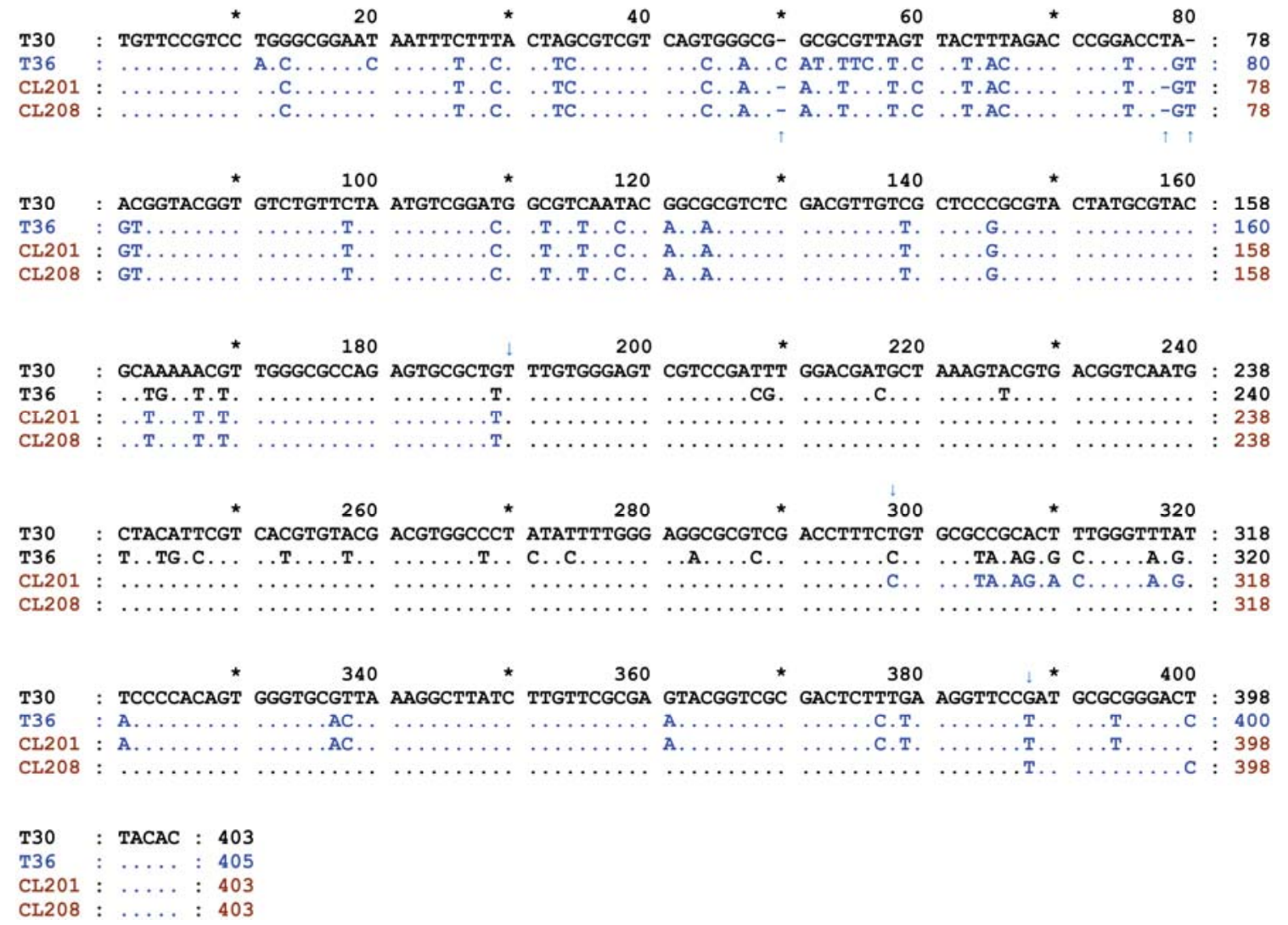

Fig. 5. Comparison of T30 and T36 genotypic isolate sequence with recombinant clones sequence from mixed genotypic isolate FS627 and its aphid-transmitted subisolates. Symbols $\uparrow$ and $\downarrow$ indicate the gaps and recombinant sequence presence in isolate FS627 (CL201) and subisolate AT9.4 (CL208), respectively.

showed that individual CTV isolates are composed of a population of genome variants (haplotypes) and the haplotypes' distribution could be altered after host change in aphid transmission. Our results supported the use of single or multiple aphids as a separation tool for subisolates from the CTV complex.

To avoid the misunderstanding of genotype classification, we successfully used SSCP followed by sequence analysis to identify the most frequently transmissible CTV isolates from a mixed virus source. All the first- and second-level AT subisolates exhibited no major symptom differences compared with their source isolate. The SSCP patterns of the subisolates were of three types. They were either like the FS627 source isolate or like isolates T36 or T30. The most common AT genotype was T30. In a previous study (4) using MMM to characterize the AT genotypes from FS627, VT genotype isolates were found in only second-level AT but were mixed with either T36 or T30 genotypes. In the present study, no VT-like genotype-specific banding pattern was found in SSCP analysis from CPG and 5' regions. Screening of the transformed colonies of amplified products is another way to determine the presence of the genotypes within AT subisolates. Following SSCP screening, the divergent genotypic population was obtained from CPG and from the 697 to 1,484 nt in the $5^{\prime}$ region. Clearly, our results indicated that the Florida isolate FS627 contains a T36 population that is more prevalent than the T30 and VT genotypes. However, the T30 genotype was more frequently aphid transmitted than the T36 and VT genotypes from the mixed population. Huang et al. (9) showed that the T36 genotype was more easily transmitted than the T30 genotype by single BCA transmissions from T36/T30 genotype mixtures. Our result showed that $\mathrm{T} 30$ is the most frequently transmitted genotype when the genotype is mixed with either T36, VT, or both genotypes. Differences in the data may be due to the number of transmissions, number of aphids used, isolates used, and differences in host plants. In the Huang study (9), the source isolates Y3, Y6, Y7, and Y23 are either T36, T30, or a combination of T36- and T30-like field isolates whereas the studied isolate FS627 is a mixture of T36, T30, and VT-like isolates. In the above study (9), the source plants were 'Duncan' grapefruit and the receptor plants were 'Mexican' lime, whereas sweet orange and Mexican lime were used as source and receptor plants in our study. In relation to aphid transmission, our conclusions were based on second-level SAT and multiple aphid transmission from first-level SAT (SMAT) whereas Huang et al. (9) concluded their experiment results based on first-level SAT. Based on the comparative study between susceptible host, virulent virus, and vector interactions, we suggest that, under certain conditions, BCA transmitted a T30-like CTV population more frequently than T36. Further research on intra- and interrelationships of the 


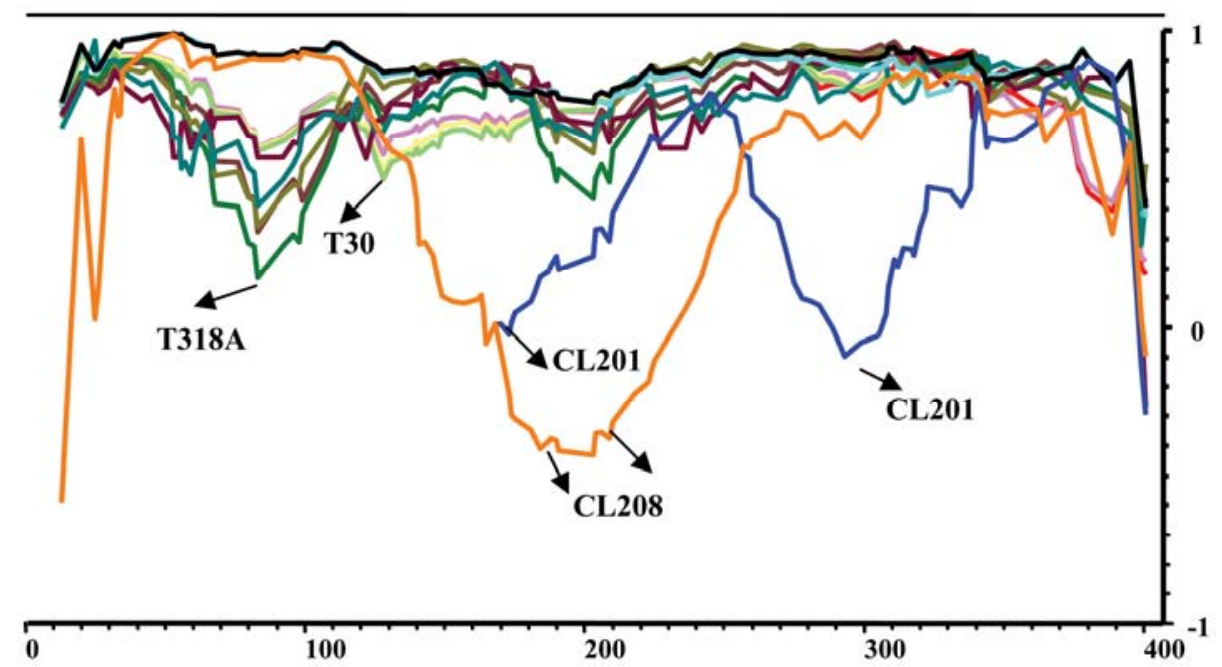

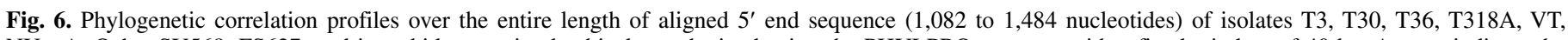

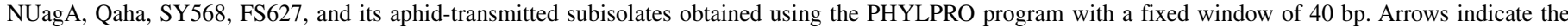
recombinant signals for haplotypes CL201 and CL208.

above-mentioned factors should help to determine the aphid transmission of CTV complexes. Recently, Sentandreu et al. (25) showed that hosts can be an important evolutionary factor for CTV isolates. They found no evidence of recombination as a significance factor during p18 and p20 gene evolution in two CTV isolates. They concluded that changes in the composition of viral populations may result in increased pathogenicity.

In our study, no VT-type sequences were obtained from the CPG and the 697 to $1,484 \mathrm{nt}$ in the 5' region. However, sequencing of the genotype-specific VTPOL primer-pair-amplified products confirmed the presence of the VT genotype from source plants as well as from two AT subisolates, each one from the first and second levels (Fig. 4). However, the VTPOL-amplified products from six second-level AT transmission plants had a 98 to 99\% sequence identity with the T30 genotype. From these results, we suggest that MMM amplification may not indicate that an isolate has close sequence similarity with a particular genotype and, thus, may not occupy the same genogroup in the phylogenetic tree.

Phylogenetic analysis of the three different amplified regions showed the existence of two to four populations in FS627 and its subisolates (T30, T36, VT, and new variants). Either silent (synonymous) or nonsynonymous mutations are the basis of all the known genotypes. Further analysis of the 1,082 to 1,484 nt from the 5' terminal region using PHYLPRO showed that some clone sequences of FS627 and AT9.4 subisolates were evolved by homologous recombination (Fig. 6). The above data may explain the reasons for differences observed in the phylogenetic association of CL201 and CL208 with T30, T36, and T318A isolates. This finding supports the existence of new variant sequence types among the studied isolate and subisolates and explains the topology of the phylogenetic tree (Fig. 3B). Detection of recombinant events in the sequence of some isolates suggests that recombination may have played a significant role in the evolution of CTV genotypes, increasing genetic diversity and adaptability. Previous work suggests that homologous and nonhomologous recombination may be a frequent phenomenon in CTV $(2,13,23,27)$, because it is common to find mixtures of genotypes in infected plants (21).

The intraisolate genetic diversity was very low compared with interisolate genetic diversity in most cases. Other viruses of the family Closteroviridae, such as Beet pseudo yellows virus and Cucurbit yellow stunting disorder virus, have given similar results (24). However, some isolates showed a high intraisolate genetic diversity and some haplotypes had more genetic similarity to those of other CTV isolates. For example, in Figure 3B, the VTPOL-amplified product of group II-b subisolates showed similarity with the T30POL-amplified product sequences. The genetic diversity in CTV population biology observed here appears to fit the quasispecies model that is rare among plant viruses. This is may be attributed to the combined effects of selection pressure to regenerate functional genomes by recombination of the genomic segments (6). Multiple CTV subpopulations with differing fitness levels under different selection pressures may be maintained by a combination of pressures in a shifting cloud form. From our study, we can conclude that there were two major (T30- and T36-like) and one minor (VT-like) populations present in the FS627 source isolate and various combinations of these in the AT subisolates. New variants which contained a combination of T36 and T30 nucleotide sequences were developed through recombination. Transmission of recombinants by aphid vectors may result in changes in virus populations, which may result in economic consequences for citrus production.

\section{ACKNOWLEDGMENTS}

We thank D. Howd for conducting aphid transmission, keeping inventory, and maintaining the FS627 and its aphid-transmitted subisolates in the greenhouse; S. Shanker from the DNA sequencing core facility, University of Florida, Gainesville for sequencing; and the United States Department of Agriculture Specific Cooperative Agreement Exotic Citrus Disease Grant for financial assistance during this investigation.

\section{LITERATURE CITED}

1. Albiach-Marti, M. R., Guerri, J., Hermoso de Mendoza, A., Laigret, F., Ballester-Olmos J. F., and Moreno, P. 2000. Aphid transmission alters the genomic and defective RNA populations of Citrus tristeza virus isolates. Phytopathology 90:134-138

2. Ayllon, M. A., Lopez, C., Navas-Castillo, J., Mawassi, M., Dawson, W. O., Guerri, J., Flores, R., and Moreno, P. 1999. New defective RNAs from Citrus tristeza virus: evidence for a replicase-driven template switching mechanism in their generation. J. Gen. Virol. 80:817-821.

3. Ayllon, M. A., Rubio, L., Moya, A., Guerri, J., and Moreno, P. 1999. The haplotype distribution of two genes of Citrus tristeza virus is altered after host change in aphid transmission. Virology 255:32-39.

4. Brlansky, R. H., Damsteegt, V. D., Howd, D. S., and Roy, A. 2003. Molecular analyses of Citrus tristeza virus subisolates separated by aphid transmission. Plant Dis. 87:397-401.

5. Broadbent, P., Brlansky, R. H., and Indsto, J. 1996. Biological characterization of Australian isolates of Citrus tristeza virus and separation of subisolates by single aphid transmissions. Plant Dis. 80:329-333.

6. Garcia-Arenal, F., Fraile, A., and Malpica, J. M. 2001. Variability and 
genetic structure of plant virus populations. Annu. Rev. Phytopathol. 39:157-186.

7. Halbert, S. E., Genc, H., Cevik, B., Brown, L. G., Rosales, I. M., Keremane, L. M., Pomerinke, M., Davison, D. A., Lee, R. F., and Niblett, C. L. 2004. Distribution and characterization of Citrus tristeza virus in south Florida following establishment of Toxoptera citricida. Plant Dis. 88:935-941.

8. Hilf, M. E., Karasev, A. N., Albiach-Marti, R. M., Dawson, W. O., and Garnsey, S. M. 1999. Two paths of sequence divergence in the Citrus tristeza virus complex. Phytopathology 89:336-342.

9. Huang, Z., Rundell, P. A., Guan, X., and Powell, C. A. 2005. Evaluation of the transmission of different field sources of Citrus tristeza virus and the separation of different genotypes by single brown citrus aphids. Hortic. Sci. 40:687-690.

10. Karasev, A. V. 2000. Genetic diversity and evolution of closteroviruses. Annu. Rev. Phytopathol. 38:293-324.

11. Karasev, A. V., Boyko, V. P., Gowda, S., Nikolaev, O. N., Hilf, M. E., Koonin, E. V., Niblett, C. L., Cline, K., Gumpf, D., Lee, R. F., Garnsey, S. M., Lewandowski, D. J., and Dawson, W. O. 1995. Complete sequence of Citrus tristeza virus genome. Virology 208:511-520.

12. Kumar, S., Tamura K., and Nei, M. 2004. MEGA3: integrated software for molecular evolutionary genetics analysis and sequence alignment. Brief. Bioinf. 5:150-163.

13. Mawassi, M., Karasev, A. V., Mietkiewska, E., Gafny, R., Lee, R. F., Dawson, W. O., and Bar-Joseph, M. 1995. Defective RNA molecules associated with Citrus tristeza virus. Virology 208:383-387.

14. Mawassi, M. E., Mietkiewska, E., Gofman, R., Yang, G., and Bar-Joseph, M. 1996. Unusual sequence relationships between two isolates of Citrus tristeza virus. J. Gen. Virol. 77:2359-2364.

15. Niblett, C. L., Genc, H., Cevik, B., Halbert, S., Brown, L., Nolasco, G., Bonacalza, B., Manjunath, K. L., Febres, V. J., Pappu, H. R., and Lee, R. F. 2000. Progress on strain differentiation of Citrus tristeza virus and its application to the epidemiology of citrus tristeza disease. Virus Res. 71:97-106.

16. Nicholas, K. B., and Nicholas, H. B., Jr. 1997. GeneDoc: A tool for editing and annotating multiple sequence alignments. www.psc.edu/ biomed/genedoc

17. Pappu, H. R., Karasev, A. V., Anderson, E. J., Pappu, S. S., Hilf, M. E., Febres, V. J., Eckloff, R. M. G., McCaffery, M., Boyko, V., Gowda, S., Dolja, V. V., Koonin, E. V., Gumpf, D., Cline, K. C., Garnsey, S. M., Dawson, W. O., Lee, R. F., and Niblett, C. L. 1994. Nucleotide sequence and organization of eight $3^{\prime}$ open reading frames of the Citrus tristeza closterovirus genome. Virology 199:35-46.

18. Permar, T. A., Garnsey, S. M., Gumpf, D. J., and Lee, R. F. 1990. A monoclonal antibody that discriminates strains of citrus tristeza virus. Phytopathology 80:224-228.

19. Raccah B., Loebenstein, G., and Singer S. 1980. Aphid transmissibility of Citrus tristeza virus in infected citrus trees. Phytopathology 70:89-93.

20. Roy, A., and Brlansky, R. H. 2004. Genotype classification and molecular evidence for the presence of mixed infections in Indian Citrus tristeza virus isolates. Arch. Virol. 149:1911-1929.

21. Roy, A., Manjunath, K. L., and Brlansky, R. H. 2005. Assessment of sequence diversity in the $5^{\prime}$ terminal region of Citrus tristeza virus from India. Virus Res. 113:132-142.

22. Rubio, L., Ayllon, M. A., Guerri, J., Pappu, H., Niblett, C. L., and Moreno, P. 1996. Differentiation of Citrus tristeza closterovirus (CTV) isolates by single-strand conformation polymorphism analysis of the coat protein gene. Ann. Appl. Biol. 129:479-489.

23. Rubio, L., Ayllon, M. A., Kong, P., Fernandez, A., Polek, M. L., Guerri, J., Moreno, P., and Falk, B. W. 2001. Genetic variation of Citrus tristeza virus isolates from California and Spain: Evidence for mixed infections and recombination. J. Virol. 75:8054-8062.

24. Rubio, L., Soong, J., Kao, J., and Falk, B. W. 1999. Geographic distribution and molecular variation of isolates of three whitefly-borne closteroviruses of cucurbits: Lettuce infectious yellows virus, cucurbit yellow stunting disorder virus, and beet pseudo-yellows virus. Phytopathology 89:707-711.

25. Sentandreu, V., Castro, J. A., Ayllon, M. A., Rubio, L., Guerri, J., Gonzalez-Candelas, F., Moreno, P., and Moya, A. 2006. Evolutionary analysis of genetic variation observed in Citrus tristeza virus (CTV) after host passage. Arch. Virol. 151:875-894.

26. Thompson, J. D., Gibson, T. J., Plewniak, F., Jeanmougin, F., and Higgins, D. G. 1997. The Clustal X windows interface: Flexible strategies for multiple sequence alignment aided by quality analysis tools. Nucleic Acids Res. 24:4876-4882.

27. Vives, M. C., Rubio, L., Sambadea, A., Mirkov, T. E., Morenoa, P., and Guerri, J. 2005. Evidence of multiple recombination events between two RNA sequence variants within a Citrus tristeza virus isolate. Virology 331:232-237.

28. Weiller, G. F. 1998. Phylogenetic profiles: a graphical method for detecting genetic recombinations in homologous sequences. Mol. Biol. Evol. 15:326-335. 